\title{
A potência dos Discursos: um pensar sobre as mulheres, a natureza e o Pampa
}

\author{
La potencia de los Discursos: un pensar sobre las mujeres, la naturaleza y \\ lo Pampa
}

The power of Discourses: a thought about women, nature, and Pampa

\author{
Juliana Corrêa Pereira Schlee ${ }^{1}$ \\ Isabel Ribeiro Marques ${ }^{2}$ \\ Renata Lobato Schlee ${ }^{3}$
}

\begin{abstract}
Resumo
Em constante desassossego que nos acompanha, problematizamos alguns ditos e não ditos atrelados a discursos relacionados a mulheres, a natureza e o pampa do Rio Grande do Sul. Esses olhares que tanto se inquietam se sustentam sob o aporte teórico de autores da vertente teórica denominada filosofia da diferença, como Michel Foucault, Gilles Deleuze e Friedrich Nietzsche juntamente a intercessores que se debruçam sobre as questões de gênero, como Sandra Garcia, Mary Castro e Miriam Abromovay. Analisamos algumas construções históricas e culturais que evidenciam um antropocentrismo, bastante marcado por um androcentrismo neste Pampa. Entrelaçadas nessas teias discursivas, pinçamos mulheres, e colocamos algumas inquietações como potência para pensarmos as tramas discursivas que se articulam nesses jogos, nessas relações que se pautam na figura masculina e atribuem às mulheres, a tarefa do cuidado com a natureza. Assim pensamos no quanto esses discursos são fabricados em processos culturais, sustentados em relações de poder que fazem emergir verdades e saberes dados como naturais nos interstícios da educação ambiental.
\end{abstract}

Palavras-Chave: Discurso; educação ambiental; mulheres; natureza; pampa.

\section{Resumen}

En constante desasosiego que nos acompaña, problematizamos algunos dichos y no dichos atados a discursos relacionados a mujeres, la naturaleza y lo pampa del estado de Rio Grande do Sul, Brasil. Estas miradas que tanto se inquietan se sostienen bajo el aporte teórico de autores de la vertiente teórica denominada filosofía de la diferencia, como Michel Foucault, Gilles Deleuze y Friedrich Nietzsche junto a intercesores que se inclinan sobre las cuestiones de género, como Sandra García, Mary Castro y Miriam Abromovay. Analizamos algunas construcciones históricas y culturales que evidencian un antropocentrismo, bastante marcado por un androcentrismo en esta Pampa. Entrelazadas en esas telas discursivas, pinzamos mujeres, y ponemos algunas inquietudes como potencia para pensar las tramas discursivas que se articulan en esos juegos, en esas relaciones que se pautan en la figura masculina y atribuyen a las mujeres, la tarea del cuidado con la naturaleza. Así

\footnotetext{
${ }^{1}$ Mestranda do Programa de Educação Ambiental pela Universidade Federal do Rio Grande - FURG. Integrante do Grupo de Estudos em Educação, Cultura, Ambiente e Filosofia - GEECAF/ FURG; Bolsista CAPES; Rio Grande, Rio Grande do Sul, Brasil. E-mail: julianaschlee@gmail.com

${ }^{1}$ Doutoranda em Educação Ambiental - FURG. Mestre em Educação e Tecnologia - IF Sul, Integrante do Grupo de Pesquisa Educação, Cultura, Ambiente e Filosofia - GEECAF/FURG. Bolsista CAPES. Rio Grande, Rio Grande do Sul, Brasil. E-mail: isabel.marques.82@gmail.com

${ }^{2}$ Mestre e doutora em educação ambiental pela Universidade Federal do Rio Grande - PPGEA /FURG. Integrante do Grupo de Estudos em Educação, Cultura, Ambiente e Filosofia - GEECAF / FURG. Rio Grande do Sul / Brasil. Contato: renataschlee@gmail.com
} 
pensamos en cuántos discursos se fabrican en procesos culturales, sostenidos en relaciones de poder que hacen emerger verdades y saberes dados como naturales en los intersticios de la educación ambiental.

Palavras-clave: Discursos; educación ambiental; mujeres; naturaleza; pampa.

\begin{abstract}
In a constant unrest which follows us, we problematize some said and unsaid connected to discourses related to women, nature, and Pampa of Rio Grande do Sul. These restless views are based on the contribution of authors of a theoretical idea called philosophy of difference. In such manner, we selected Michel Foucault, Gilles Deleuze, and Friedrich Nietzsche, together with researchers from gender area, like Sandra Garcia, Mary Castro, and Miriam Abromovay. In this way, we analyzed some historical and cultural constructions that show an anthropocentrism quite marked by an androcentrism in the Pampa. Intertwined in these discursive webs, we selected women and put some unrests as power to think the discursive plots that are articulated in these games, in these relationships that are based on the male figure, attributing to women the task of taking care of nature. Therefore, we thought about how these discourses are made in cultural processes based on power relations, which make emerge truths and ideas known as natural in the interstices of environmental education.
\end{abstract}

Keywords: Discourse; environmental education; women; nature; Pampa.

\title{
1. Introdução
}

A presente escrita é tecida com inquietações que permeiam olhares provenientes de pesquisadoras que buscam guarida em autores da vertente denominada Filosofia da Diferença e, que possuem em comum um constante desassossego em relação a verdades tidas como dadas. Nesse sentido, olhamos para as mulheres, a natureza e o pampa, sob constante articulação com conceitos como verdade, poder e discurso, vislumbrando-os em teias discursivas que se enredam em nossos modos de vida.

O trabalho é pensando em dois momentos: no primeiro, fazemos uma contextualização sobre o campo de saber da educação ambiental diante da força do imagético que de forma pedagógica nos ensina sobre as fabricações discursivas de mulher e natureza no Pampa.

Acreditamos na conveniência de olhar para o campo de saber da educação ambiental. Se fizermos um breve retrospecto da caminhada ambiental, vislumbramos a questão antropocêntrica que permeando uma forma de ser e existir na modernidade, preenche o campo da educação ambiental - EA. Interessante que o homem aparece tanto como o destruidor e causador das mazelas ambientais como o ser que poderá dar conta dos tantos problemas ocasionados nos últimos séculos. Uma modernidade que se faz antropocêntrica e androcêntrica.

Assim, trazemos em evidência, sobre a construção discursiva de mulher e de natureza no Pampa, um olhar sob as lentes da educação ambiental que se provoca em discutir como naturalizamos essa forma de ser e existir centrada no humanismo e na figura do masculino.

\section{Repensando olhares}


Ao longo dos últimos séculos, o ser humano vem inventando outras expressões diante do que toma por natureza. Após a revolução industrial, o funcionamento humano modificou-se rapidamente e de forma bastante diferente do que até então havíamos vivenciado. Nossas relações sociais, relações com o trabalho e com a organização do espaço trouxeram funcionamentos diferentes e que desafiam nossos entendimentos organizacionais. Tornamo-nos mais urbanos e nossa percepção de natureza no ocidente foi trazendo novas formas de relacionar-se com o que passamos a significar de natural.

Hoje, temos na agenda de governos e sociedade civil organizada um temor pela perda do natural, algo que captura e se faz hegemônico em diferentes partes do planeta. Verdades de um tempo, de nossa modernidade e assumidas de diferentes maneiras.

A natureza vai sendo inventada a partir do lugar que estabelecemos para ela e a partir da posição que assumimos diante dela. A interação humana com os diferentes elementos desse lugar se torna classificável e hierárquica através da voz da ciência que qualifica modos de agir. Isso é, então, um modo moderno de existir, no qual vamos estabelecendo a necessidade de proteção pelas lentes da ciência. E a educação ambiental ocupa um papel considerável neste desafio moderno, pois estabelece os modos de atuação humana diante do ambiente.

$\mathrm{E}$ as fotografias, um imagético que nos ensina e é bastante utilizado nas diferentes atividades de EA, trazem, provocam, operam relações e percepções na relação entre o humano e a natureza. Tencionando esse modo de olhar para natureza como frágil e virgem, e o humano como vilão, procuramos pensar nessas invenções em sua constituição, problematizando como fomos nos tornando apartados e devastadores/colaborativos e protetores. Há sempre uma dualidade que vai sendo reforçada: ou estamos destruindo ou estamos protegendo e, ainda, mesmo sendo trazido como protetor da natureza, o humano é colocado fora dela. O humano como protetor e/ou destruidor; a dualidade colocada e afirmada, uma dualidade que reforça natureza e cultura como distantes e separadas; a natureza dada como fora do humano e como algo que precisa ser recuperada depois da destruição que esse humano provoca a partir da modernidade.

Percebemos uma construção imagética, onde o humano está apartado do que hegemonicamente toma por natureza. Reforçamos este ponto de vista.

A predominância do humano sobre todas as coisas e criaturas do mundo tem seu marco filosófico moderno fundamental no pensamento de Descartes. Mas se nosso intuito é compreender este momento, precisamos nos voltar para os próprios antecedentes do pensamento cartesiano. Os antecedentes históricos da filosofia de Descartes podem ser encontrados naquilo que de um modo geral e não muito preciso chamamos de humanismo. A predominância do humano inicia-se com brilho e 
sofisticação. O humano, colocado em posição de subserviência a Deus durante toda a Idade Média, começa a dar indícios de insatisfação. É no mundo renascentista que vamos encontrar os primeiros anúncios desta mudança. Vai ser em nome do humanismo que o Homem começa a romper com a velha ordem. É o próprio Homem o grande organizador da ruptura e esta se dá de um modo múltiplo e complexo, na arte, política, religião e filosofia (GRÜN, 1996, p. 24).

São os humanistas que vão examinar criticamente, no período do renascimento no ocidente, o funcionamento da natureza, dos homens e das relações estabelecidas. Há uma busca por tomar seus destinos, organizá-los e determiná-los. As explicações teocêntricas do período medieval vão sendo questionadas e uma nova mentalidade vai se destacando. Uma mentalidade que se via como herdeira direta da antiguidade clássica, reafirmando a cultura greco-romana. Houve, assim, uma grande mudança no campo das artes, filosofia, ciência e literatura, como disse Grün (IBIDEM).

Todas essas mudanças, ou eclosão de movimentos artísticos, culturais, filosóficos e científicos caracterizam transformações entre os séculos XIV e XVI, que enfatizavam a cultura laica, racional e científica - o que passa a evidenciar, mais tarde, nos séculos XVII e XVIII, um movimento de ideias chamado iluminismo que, na esteira do renascimento, aponta para a universalidade, a individualidade e a autonomia como princípios básicos. Aqui, nos interessa pensar como fomos nos constituindo, no ocidente, a partir dessas grandes insígnias. Ou melhor: de que forma alguns emblemas, a partir do renascimento, se fizeram fortes, inseridos em relações de poder e saber, em um vai e vem constante de forças discursivas que foi se constituindo em ideias de natureza que podem estar atualizadas no hoje.

Assim se fez o renascimento, como dizia Grün (IBIDEM), no rompimento, na ruptura com a velha ordem, surgindo, assim, outras formas de se relacionar. O humano ocidental estava passando por mudanças bastante fortes que trouxeram transformações consigo, no social e ambiental - transformações sustentadas pelo classicismo, com a retomada dos valores da antiguidade; a valorização dos prazeres terrenos e do corpo; o naturalismo, com o domínio do homem sobre a natureza, levando a um racionalismo; o antropocentrismo, no qual o homem passou a colocar-se como o centro do universo. Ainda com Grün, referindose a esse período,

[...] A natureza não tem mais um tempo que lhe seja próprio, com seus ciclos e suas relações de ecodependência de cadeias tróficas. O tempo da natureza passa a ser o tempo da racionalidade humana. A natureza é mercantilizada. Tempo, negócios e natureza passam a andar juntos. Relações de mercado, natureza e lógica temporal antropocêntrica passam a formar um sistema complexo de inter-relações. De agora em diante, "tempo é dinheiro" - eis o novo lema (GRÜN, 1996, p. 25).

$\mathrm{O}$ mundo moderno investe em oportunidades e não mais na sorte e acaso. $\mathrm{O}$ investimento passa a ser o de criar ocasiões e situações que fortaleçam a atuação humana 
sobre seu mundo. Há jogos e estratégias de saber e poder que lançam e constituem uma história iluminista que se espalha em modelos de estrutura colonial, escravocrata, mercantil, industrial. A partir dos séculos XVI e XVII (principalmente), essa influência toma corpo e chega aqui na América, no Pampa. Essa nova construção de espaço-tempo se espalha pelo ocidente em modos e fabricações de natureza.

\section{Entrelaçamentos entre mulheres e natureza}

Atualmente, com o investimento do campo da EA, temos as discussões do papel humano frente ao que tomamos por natureza e evidenciando o humano, discutimos o quanto o papel feminino é colocado em posição de cuidado do planeta. Para isso buscamos em alguns autores problematizações potentes para esta escrita, como Garcia (1992, p.163) que nos provoca: "qual é a especificidade da relação entre mulher e meio ambiente? Ela é distinta da relação homem/meio ambiente?"

As questões trazidas nos potencializam a pensar o quanto esses discursos são fabricados na cultura que, atrelados por relações de poder, fazem emergir verdades e saberes, dados como naturais nas relações entre as mulheres e a natureza e o pampa. No entanto, esta relação tem sido alvo de muitas divergências e antagonismos: se por um lado as mulheres são vistas com laços especiais com a natureza, como salvadoras naturais da natureza, por outro lado reconhecem que as mulheres e a natureza são simultaneamente subjugadas, de formas históricas e culturais específicas (BRAIDOTTI et al, 1994). Aproveitando-se de Deleuze (1976,p. 3) que nos provoca ao dizer que não se encontra o sentido de alguma coisa, se não soubermos qual é a força que se se apropria da coisa, que dela se apodera ou nela se exprime e, com a finalidade de trazer imagens para esta discussão sobre o que tomamos naturalmente, como verdadeiro nas relações com a natureza realizamos algumas buscas na internet, primeiramente pesquisamos no portal de buscas Google: Homem e Natureza (Figura 1) e Mulher e Natureza (Figura 2) e posteriormente nos debruçamos as análises em fotografias da argentina Celine Frers presentes no site oficial.

Nesta primeira busca obtemos alguns resultados: 
RELACult - Revista Latino-Americana de Estudos em Cultura e Sociedade

Revista Latinoamericana de Estudios en Cultura y Sociedad | Latin American Journal of Studies in Culture and Society V. 05, ed. especial, abr., 2019, artigo n ${ }^{\circ}$ 1265| claec.org/relacult |e-ISSN: 2525-7870

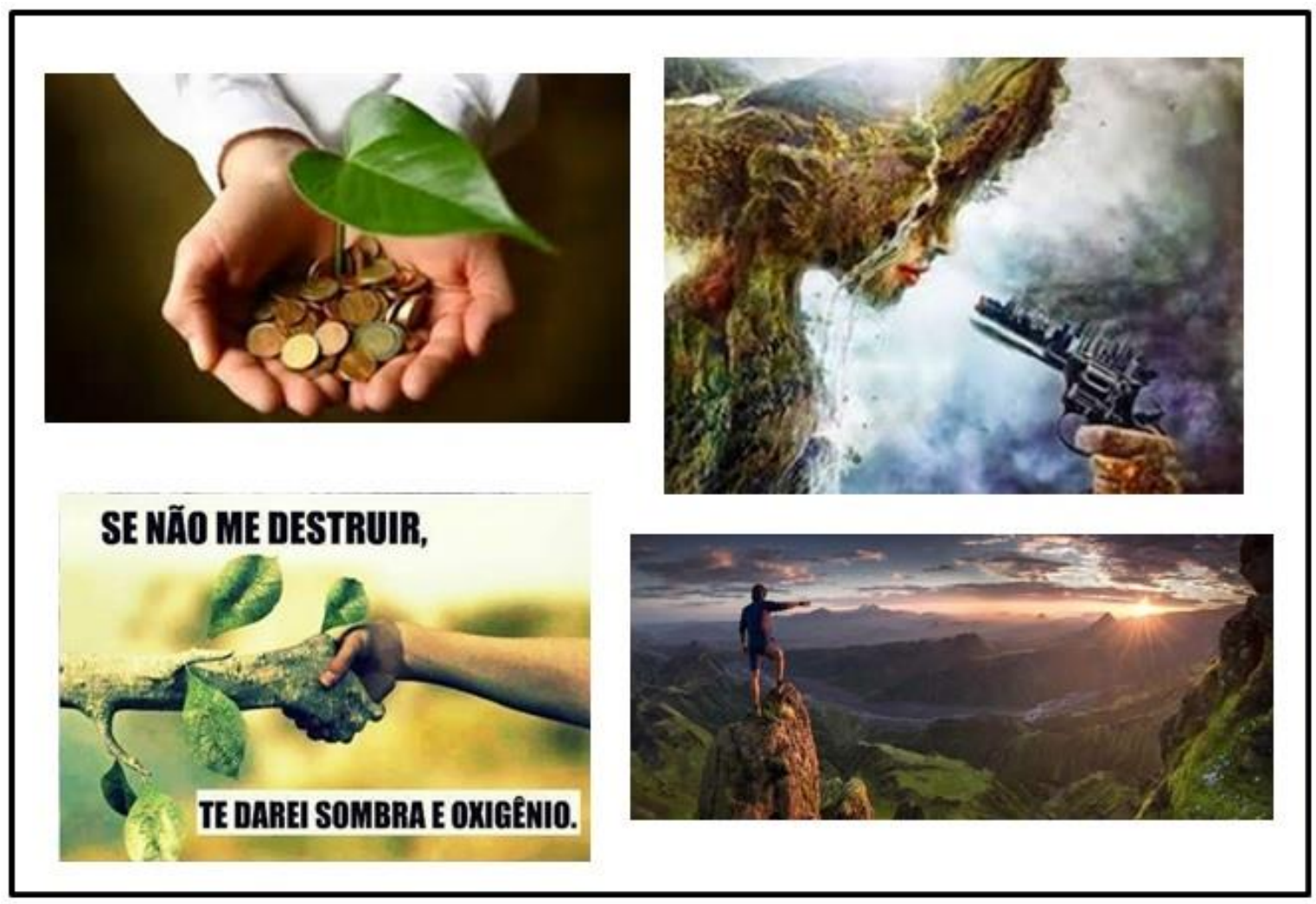

Figura 1 - Composição de algumas imagens sobre Homem e Natureza

Fonte: Google, 2018.

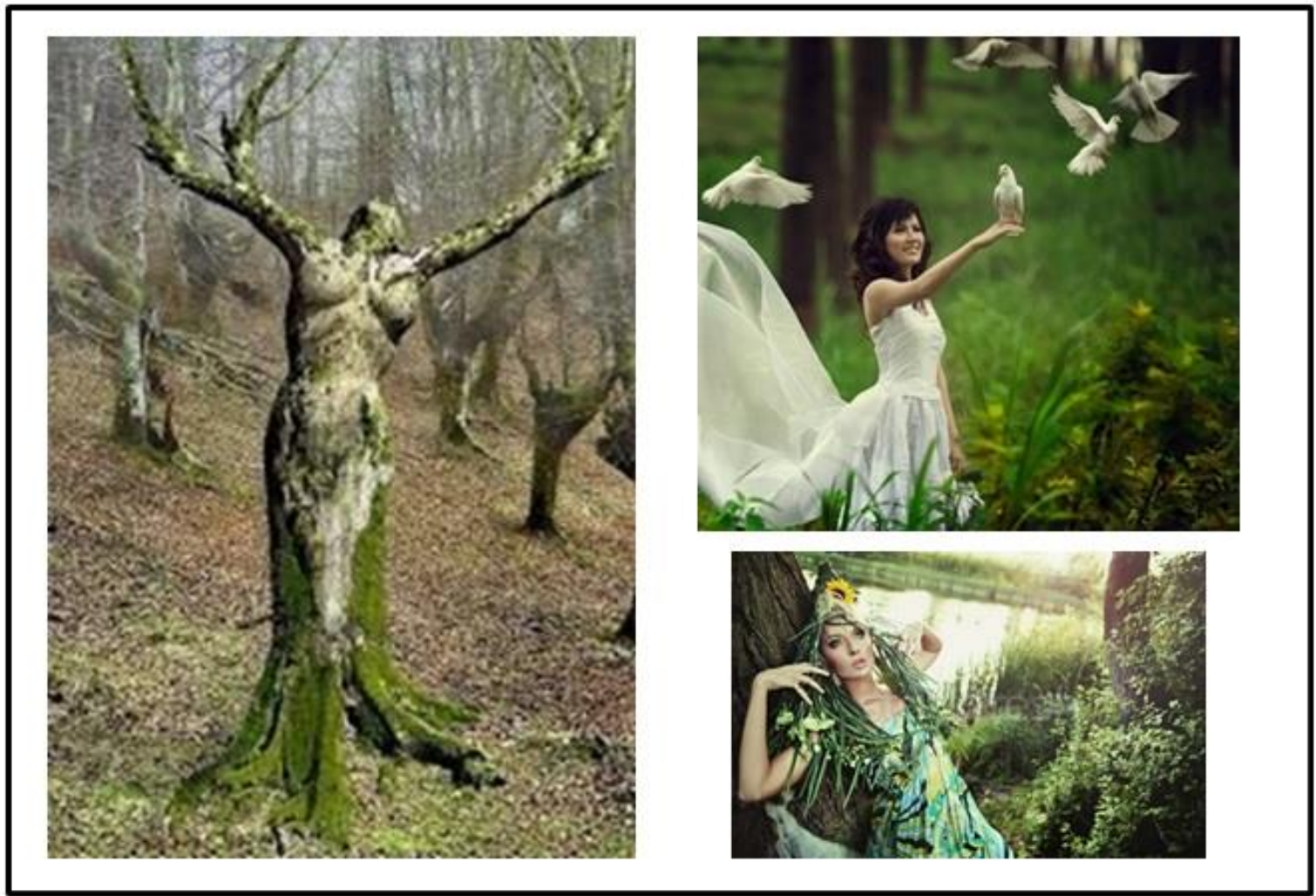

Figura 2 - Composição de algumas imagens sobre Mulher e Natureza

Fonte: Google, 2018. 
É possível observar na Figura 1 algumas imagens ilustram as relações de antropocentrismo que discutimos anteriormente: os homens figurando, mãos segurando moedas e uma planta, mão masculina com arma ameaçando a natureza, relações de contrato "se não me destruir, te darei sombra e oxigênio" e na última imagem há um homem contemplando o pôr-do-sol em posição de destaque em relação à natureza. Muitas imagens nos remetem ao domínio da natureza, agressão, contrato, negócios.

As atribuições voltadas ao feminino, podemos observar nas imagens que compõe a Figura 2: árvore em forma de corpo feminino, mulher em meio ao verde com pombas brancas e na última imagem uma mulher em meio à natureza vestida com plantas. Ao colocar as palavras Mulher e Natureza no Google apareceram imagens que nos remetem a pensar sobre beleza, paz, harmonia, equilíbrio, cuidado, proteção, conexão, integração.

Há um dualismo presente nas imagens pesquisadas, homem/mulher, exploração/cuidado, violência/paz. Dualismos que devem ser problematizados, posições que assumimos nas maneiras de se relacionar com a natureza, importante questionarmos o que é tomado como natural nestas relações mulher/natureza, homem/natureza, além disso, atualmente, além da desconstrução da categoria mulher, estas relações não podem ser homogeneizados, tampouco suas relações universalizadas (ÁVILA, RIBEIRO E HENNING, 2016), as formas como nos relacionamos com o mundo, com a natureza e com os outras vão se constituindo histórica e culturalmente.

Preocupamo-nos aqui de não fazer inversões, trazendo à tona as mulheres como conhecedoras privilegiadas e potenciais salvadoras da natureza, mantendo as hierarquias e perpetuando o dualismo mulher/homem. A sua posição como mulheres não as qualifica para gerir o ambiente melhor do que qualquer outra pessoa, mesmo que a população das mulheres seja a mais afetada pela degradação e pela crise ambiental (BRAIDOTTI et al, 1994).

As autoras Ávila, Ribeiro e Henning (2016) ao analisar os programas globais das Nações Unidas para o Desenvolvimento - PNUD e União Internacional de Conservação da Natureza - UICN, conforme pesquisa realizada destaca a operação do gênero como dispositivo que, articulado aos dispositivos de Sustentabilidade e da Educação Ambiental, procura gerir a população para se alcançar o desenvolvimento sustentável. Nesta agenda global, o gênero vem enunciando e constituindo as mulheres na gestão do planeta para um melhor desenvolvimento no século XXI.

Articulações entre gênero e meio ambiente são tratas pelas autoras Mary Castro e Miriam Abromovay (2005) em que tratam de debates importantes sobre o movimento das mulheres no Brasil, inicialmente na Eco-92, que tratavam de debater sobre a temática 
ambiental e o desenvolvimento sustentável. A pluralidade, as multiplicidades de ser e estar neste mundo são considerações fundamentais para esta equação:

\begin{abstract}
A equação gênero e meio ambiente trouxe, ademais questões criativas e provocadoras para o debate contemporâneo sobre crise de paradigma, ou seja, sobre o conhecimento ocidental, como a reterritorialização do espaço e do ambiente, referindo-se ao corpo, à saúde, à sexualidade, ao prazer, ao telúrico. Tal equação questiona sentidos da economia política para a igualdade de vida dos indivíduos, considerando a pluralidade de ser/estar neste mundo, ultrapassa célebres dicotomias entre indivíduos e sociedade e entre natureza e cultura, dicotomias tão caras ao pensamento ocidental, defendendo o equilíbrio dos direitos dos seres humanos em sua diversidade, e o direito à casa desses seres humanos, o seu corpo e planeta (CASTRO, ABROMOVAY; 2005, p. 38).
\end{abstract}

Além de ultrapassar as dicotomias, é necessário repensar nosso olhar sobre as relações entre a natureza e a sociedade é um convite que Isabel Carvalho (2012) nos faz, para isso é preciso "desnaturalizar" os modos de ver que tínhamos como óbvios, questionando conceitos já estabilizados em muitos campos da experiência humana. Através da nossa experiência histórica podemos reinventar novas maneiras de ser e estar no mundo.

Com o auxílio dos fundamentos da Educação Ambiental podemos tensionar nossas heranças modernas, se num dado momento histórico, o homem está posicionado no centro da dos problemas de degradação e também na resolução dos problemas ambientais pautado pela racionalidade científica, agora nesta nova trama, em um momento de crise mundial convocase as mulheres para proteção e cuidado do planeta.

Atualmente, a relação das mulheres com a natureza na trama da Educação Ambiental se tornou uma posição de destaque. Mas pensamos ser importante destacar as relações das mulheres com o pampa. Qual é o lugar da mulher nesta relação? Marcas históricas e culturais pampeanas que vão posicionando homens e mulheres neste espaço-tempo.

\title{
4. Mulheres, Pampa e Natureza
}

Quando nos referimos ao território do Pampa, mapeamos uma terra que extrapola essas fronteiras políticas, linguísticas e geográficas - o Pampa, como territorialidade, é entendido para além dessas fronteiras. É Guattari (1995) quem ajuda a refletir sobre esse conceito, quando nos convida a reexaminá-lo a partir de conjuntos que atravessam a relação entre o indivíduo e a subjetividade, trazendo-o como modos de viver padronizados. Exploro essa territorialidade pampeana como uma composição histórica, como um conjunto de diferentes fatores que incluem maneiras de ser, de pensar e de viver já uniformizadas; maneiras de constituir discursos de natureza. Como afirma Foucault, 
Meu projeto não é o de fazer um trabalho de historiador, mas descobrir por que e como se estabelecem relações entre os acontecimentos discursivos. Se faço isso é com o objetivo de saber o que somos hoje. Quero concentrar meu discurso no que nos acontece hoje, no que somos, no que é nossa sociedade. Penso que há, em nossa sociedade e naquilo que somos, uma dimensão histórica profunda e (...) os acontecimentos que se produziram há séculos ou há anos são muito importantes [...] Em um certo sentido não somos nada além daquilo que foi dito há séculos, meses, semanas (FOUCAULT, 2006, p. 258).

Assim, encaramos a natureza como um discurso. Um discurso que tem seu tempo, uma verdade que se estabelece numa legitimidade de forças que compõem um espaço-tempo, um tempo histórico. No Pampa, a natureza se constrói, também, como discurso, e entender que discursos são esses nos possibilita pensarmos em quem somos e como nos atualizamos nessas fabricações históricas.

O desafio em entender a história não é simples. Nos caminhos de Foucault, começamos perguntando sobre o que ela é. Quando falamos de história, o mais comum é pensarmos em acontecimentos passados que podem ser relatados em nosso presente, tendo a capacidade de retratar esse passado exatamente como ocorreu em tempos idos. Os fatos vão sendo contados e construídos como verdades absolutas e, assim, vamos construindo entendimentos sobre o que passou, tomando esses acontecimentos como revelados, desvendados e desvelados.

Sobre outro olhar para os acontecimentos, pensamos em nossos próprios limites quando estudamos e analisamos um determinado tempo histórico. Entendo que fazemos e construímos narrativas sobre esses tempos por meio de documentos e testemunhos. Sendo assim, há sempre uma incompletude a ser considerada. Como nos lembra Veyne (2008), há sempre uma defasagem entre a reflexão da narrativa histórica e as vivências, próprias do tempo em que ocorreram. A análise histórica, na capacidade e potencialidade expressada, evidencia posições e escolhas que vamos assumindo na construção dessa narrativa. São seleções documentais e de testemunhos que vamos executando e produzindo; são narrativas que expressam olhares, tramas e atravessamentos selecionados de um espaço-tempo. É como se pinçássemos os elementos que formam nossa narrativa e, ao fazermos isso, selecionássemos, entre outros elementos, aqueles com os quais queremos trabalhar nas análises. Por isso, é possível dizer que a história é feita, também, de escolhas e renúncias.

A narrativa histórica evidencia os jogos de poder pinçados sobre um espaço-tempo, sendo que essa narrativa se dá em relações de poder que estão em evidência.

O problema é ao mesmo tempo distinguir os acontecimentos, diferenciar as redes e os níveis a que pertencem e reconstituir os fios que os ligam e que fazem com que se engendrem, uns a partir dos outros. Daí a recusa das análises que se referem ao campo simbólico ou ao campo das estruturas significantes, e o recurso às análises que se fazem em termos de genealogia das relações de força, de desenvolvimentos 
estratégicos e de táticas. Creio que aquilo que se deve ter como referência não é o grande modelo da língua e dos signos, mas sim da guerra e da batalha. A historicidade que nos domina e nos determina é belicosa e não linguística. Relações de poder, não relação de sentido. A história não tem "sentido", o que não quer dizer que seja absurda ou incoerente. Ao contrário, é inteligível e deve poder ser analisada em seus menores detalhes, mas segundo a inteligibilidade das lutas, das estratégias, das táticas [...] (FOUCAULT, 2008, p. 5).

Deslocando o entendimento da história como desveladora das verdades do passado. Entendemos que não revelamos verdades, mas assumimos uma seleção e, assim, compomos uma narrativa histórica. Construímos essa narrativa em meio à seleção que vamos executando. Construímos verdades? Sim, construímos verdades em nosso tempo. Construímos, nessa perspectiva, verdades entendidas como provisórias. Portanto, as verdades históricas são temporárias e sujeitas a revisões, novos olhares e perspectivas, estando sujeitas a novos pinçares, seleções, entendimentos e análises.

Deste modo, como podemos sustentar com Foucault (IBIDEM), o poder na ordem da produtividade estabelece, induz, forma saberes e, assim, constrói discursos. Daí a importância de analisarmos sua mecânica, problematizarmos como se dá essa produção de discursos em regimes de verdade.

O importante, creio, é que a verdade não existe fora do poder ou sem poder (não é não obstante um mito, de que seria necessário esclarecer a história e as funções - a recompensa dos espíritos livres, o filho das longas solidões, o privilégio daqueles que souberam se libertar). A verdade é deste mundo; ela é produzida nele graças a múltiplas coerções e nele produz efeitos regulamentados de poder. Cada sociedade tem seu regime de verdade, em "sua política geral" de verdade: isto é, os tipos de discursos que ela acolhe e faz funcionar como verdadeiros; os mecanismos e as instâncias que permitem distinguir os enunciados verdadeiros dos falsos, a maneira como se sanciona uns e outros; as técnicas e os procedimentos que são valorizados para a obtenção da verdade; o estatuto daqueles que têm o encargo de dizer o que funciona como verdadeiro (p.12).

De tal modo, tomamos a história como campo de possibilidades. É no pinçar das fontes, no seu manuseio, nas tramas e entrelaçamentos que vamos construindo, de acordo com nossos critérios, o que chamamos de história.

Então, falar da história do Pampa do Brasil, Uruguai e Argentina, com seus discursos de natureza, se mostrou como campo de possibilidades para destacar algumas tramas e entrelaçamentos. A história se dá, dessa forma, como campo de possibilidades de problematizações, sendo, portanto, subjetiva.

A todo momento, dão-se acontecimentos de toda espécie, e o nosso mundo é o do vir a ser; é crer-se que alguns desses acontecimentos teriam uma natureza particular, seriam 'históricos' e constituiriam a História. Ora, a questão inicial que o historismo colocava era a seguinte: o que é que distingue um evento histórico de um outro que não é? Como logo se tornou evidente que não era fácil fazer-se essa distinção, que não se podia confiar na consciência ingênua ou na consciência nacional para fazer a separação, mas que não se conseguia fazer melhor do que ela e que o objeto do debate escapava por entre os dedos, o historismo concluiu que História era subjetiva, 
que ela era a projeção de nossos valores e a resposta às perguntas que houvéssemos por bem fazer-lhe (VEYNE, 2008, p. 37).

É a descrição dessas tramas que interessa, é a descrição desses traçados que compõem a narrativa histórica que interessam. Entendemos, pois, que os fatos vão existir justamente nessas relações, produzidas e selecionadas na trama. Poderíamos dizer que trama são descrições através de caminhos selecionados pelo pesquisador, que tais descrições e traçados configuram o fato histórico. Nessa trama e cruzamento, há inúmeras possibilidades que reforçam o quanto essas narrativas se fazem em subjetividades. Assim, na esteira de Veyne (2008, p.47), podemos dizer que "acontecimentos não são totalidades, mas núcleos de relações". Ou seja, os discursos de natureza são invenções e, no caso desta tese, o que fui selecionando como um discurso de natureza no Pampa deu-se como resultado de um jogo, de um embate de forças, um confronto entre forças com seus efeitos. Além do mais, pensar em acontecimento, aqui, foi pensar nas possíveis rachaduras, rompimentos e rupturas desses discursos. O acontecimento pode ser tomado, então, enquanto efeito de atos e estratégias, como resultado de relações de poder, em que "o historiador separa, nas testemunhas e documentos, o acontecimento tal como ele o escolheu; é por esse motivo que um acontecimento jamais coincide com o cogito de seus atores e testemunhas" (IBIDEM).

Com Foucault (2008), lembramos que a história pode ser analisada numa perspectiva não linear. A história do presente se faz sem a correspondência imediata de causas e efeitos hierarquizantes, preocupando-se em estabelecer séries e as condições de sua aparição.

As noções fundamentais que se impõe agora não são mais as da consciência e da continuidade (com os problemas que lhe são correlatos, da liberdade e da causalidade), não são também as do signo e da estrutura. São as do acontecimento e da série, com o jogo de noções que lhe são ligadas; regularidade, causalidade, descontinuidade, dependência, transformação; é por esse conjunto que essa análise dos discursos sobre a qual estou pensando se articula, não certamente com a temática tradicional que os filósofos de ontem tomam ainda como a história "viva", mas com o trabalho efetivo dos historiadores. (FOUCAULT, 2008, p. 56 e 57)

Pesquisando sobre o Pampa, sua cultura, sua natureza e os sujeitos que aí se constituem e vão, ao mesmo tempo, constituindo esses discursos, buscamos, através da trama histórica, a constituição de natureza no Pampa, entendendo e assumindo a posição de fabricação desse discurso através de sujeitos contingentes, fabricados na e pela história. Foucault (2008) nos ajuda a trabalhar sobre tal aspecto quando diz:

Queria ver como estes problemas de constituição podiam ser resolvidos no interior de uma trama histórica, em vez de remetê-los a um sujeito constituinte. É preciso se livrar do sujeito constituinte, livrar-se do próprio sujeito, isto é, chegar a uma análise que possa dar conta da constituição do sujeito na trama histórica. É isto que eu chamaria de genealogia, isto é, uma forma de história que dê conta da constituição dos saberes, dos discursos, dos domínios do objeto, etc., sem ter que se referir a um 
sujeito, seja ele transcendente com relação ao campo de acontecimentos, seja perseguindo sua identidade vazia ao longo da história. (FOUCAULT, 2008, p. 7)

Assim, tomamos a genealogia como uma forma de história que nos ajudou a olhar e estudar o Pampa com seus discursos de natureza e de mulher. Um olhar que veio na tentativa de problematizar e analisar como ela se constitui na atualidade, notando, na configuração desse território, traços que se estabelecem em uma formação discursiva. Como o discurso de natureza e de mulher no Pampa.

Algumas contribuições importantes para este estudo foram os trabalhos realizados por Vieira e Henning (2014) que ao estudar a música pampiana, buscam provocar novas discussões no campo da Educação Ambiental, entendendo esta arte como uma importante ferramenta para pensarmos como vem se dando a constituição de saberes referentes à natureza e a relação do homem com a paisagem natural na região do Pampa. Assim como Schlee e Henning (2016) que trazem provocações importantes sobre o gaúcho como produção cultural, com o objetivo de problematizar as certezas e a essência gaúcha e sua relação com a natureza.

$\mathrm{Na}$ fotografia da argentina Celine Frers (nascida em 1982) são retratas as paisagens pampeanas e da Patagônia argentina. Entre seus principais trabalhos é possível destacar seu primeiro livro "Colores de Corrientes", após vieram "Cielos Patagónicos", e por fim "Tierra de Gauchos" em 2012. Neste trabalho utilizamos o albúm "Gauchos”, disponível no site oficial de Celine Frers (2017), para compreensão de como mulheres e homens pampeanos são retratados pela fotógrafa e como vão se constituindo o ser e estar no universo pampeano. Entre as 22 fotografias (Figura 03) que compõem o albúm "Gauchos" apenas uma mostra uma mulher pampeana (Figura 04) em contraste com as outras que retratam um ambiente masculino, com a imagem enaltecida do gaúcho como na Figura 05, heroico e domador. 
RELACult - Revista Latino-Americana de Estudos em Cultura e Sociedade

Revista Latinoamericana de Estudios en Cultura y Sociedad | Latin American Journal of Studies in Culture and Society V. 05, ed. especial, abr., 2019, artigo n ${ }^{\circ}$ 1265| claec.org/relacult |e-ISSN: 2525-7870

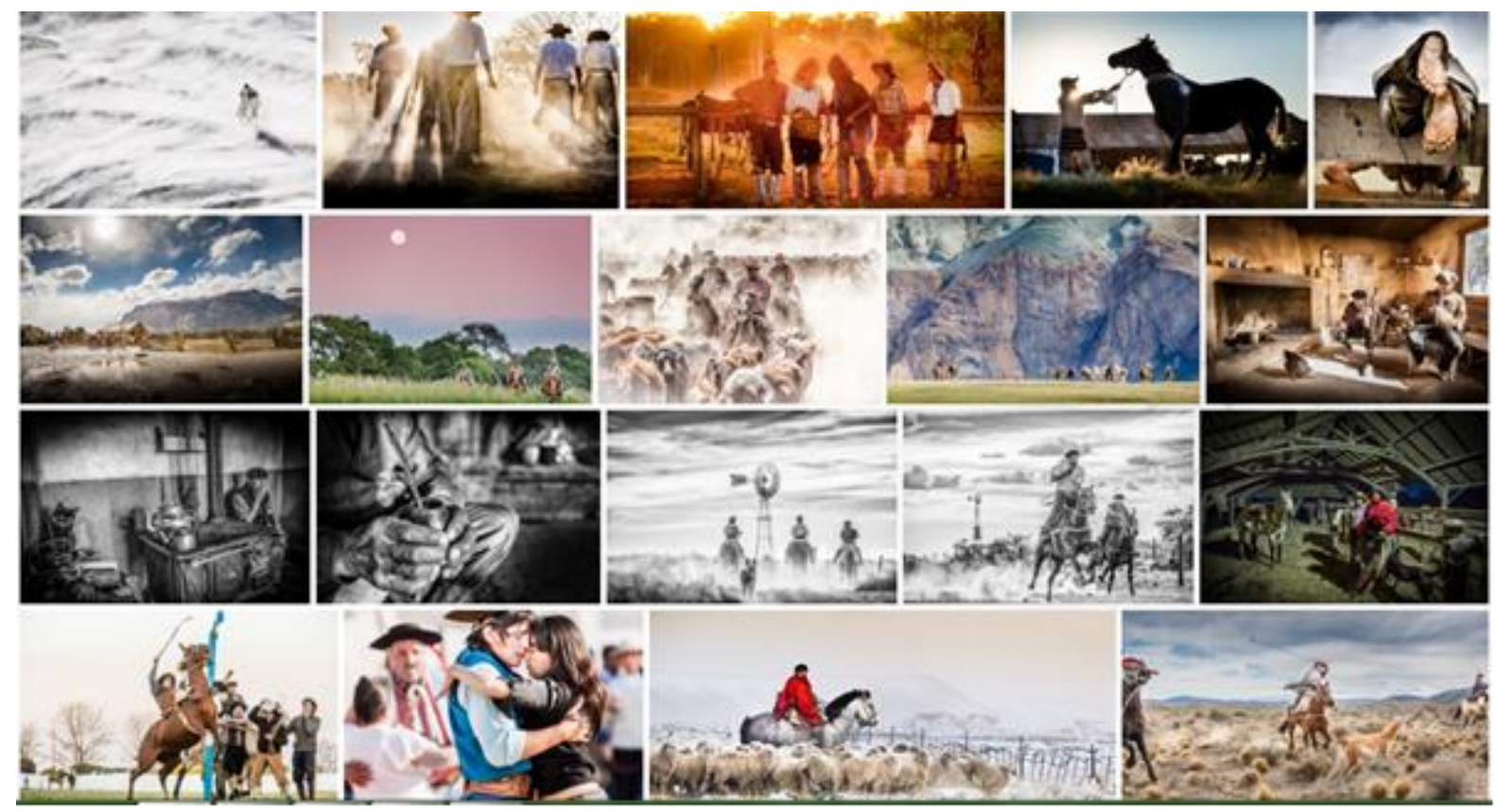

Figura 3 - Composição de algumas imagens do Álbum "Gauchos"

Fonte: FRERS, 2017.

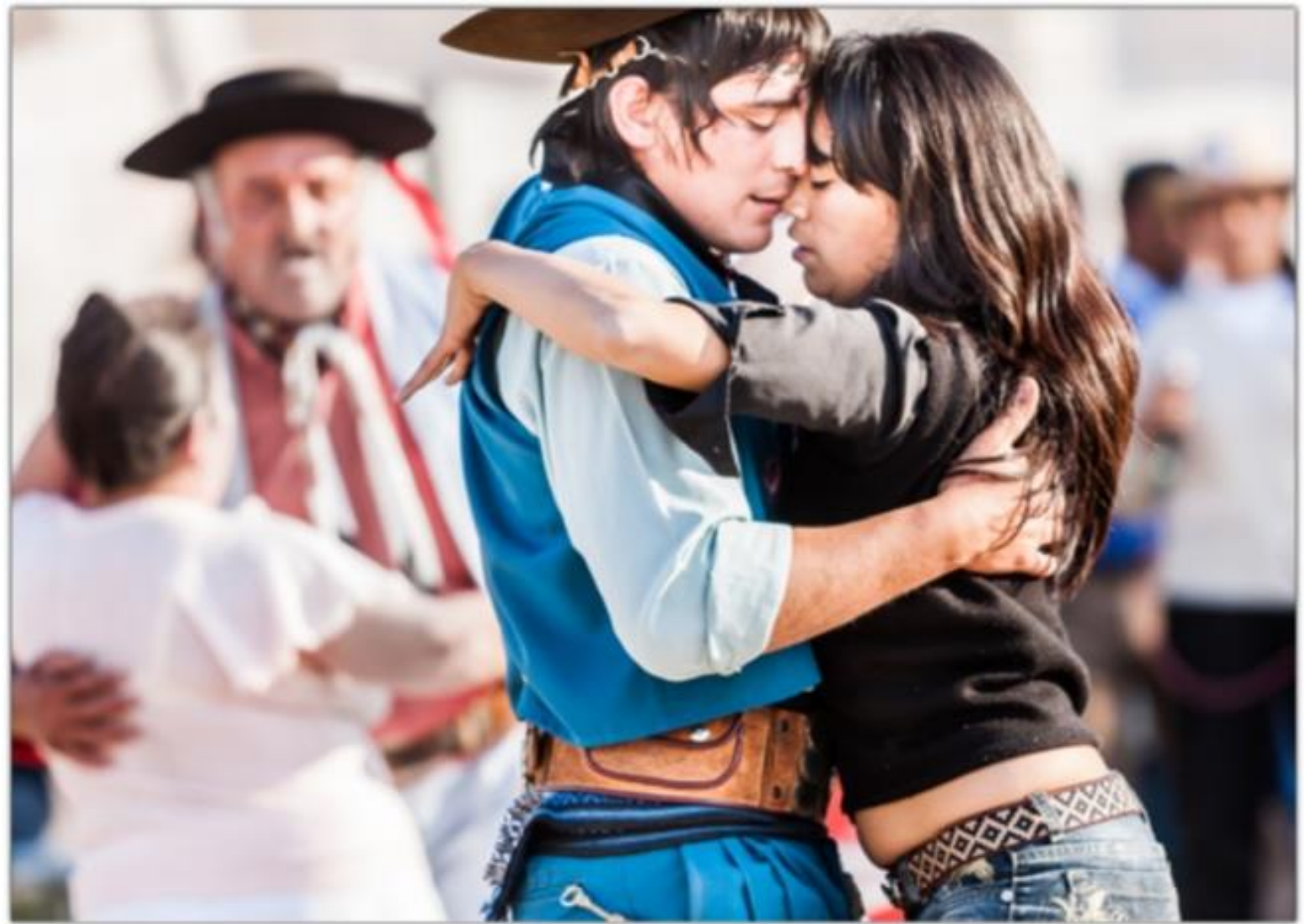

Figura 4 - Fotografia “Con el corazón latiendo” de Celine Frers (2008).

Fonte: FRERS, 2017.

Nas fotografias de Celine Frers do álbum "Gaucho" (Figura 03), assim como nas músicas pampeanas, segundo Vieira e Henning (2014) o homem aparece como um sujeito 
RELACult - Revista Latino-Americana de Estudos em Cultura e Sociedade

Revista Latinoamericana de Estudios en Cultura y Sociedad | Latin American Journal of Studies in Culture and Society V. 05, ed. especial, abr., 2019, artigo n ${ }^{\circ}$ 1265| claec.org/relacult |e-ISSN: 2525-7870

valente, heroico, bravo, viril como aquele também representado na literatura e na historiografia regional, um homem do campo, acostumado na lida com os animais, domador de cavalo, amigo e muitas vezes resistente às forças da natureza.

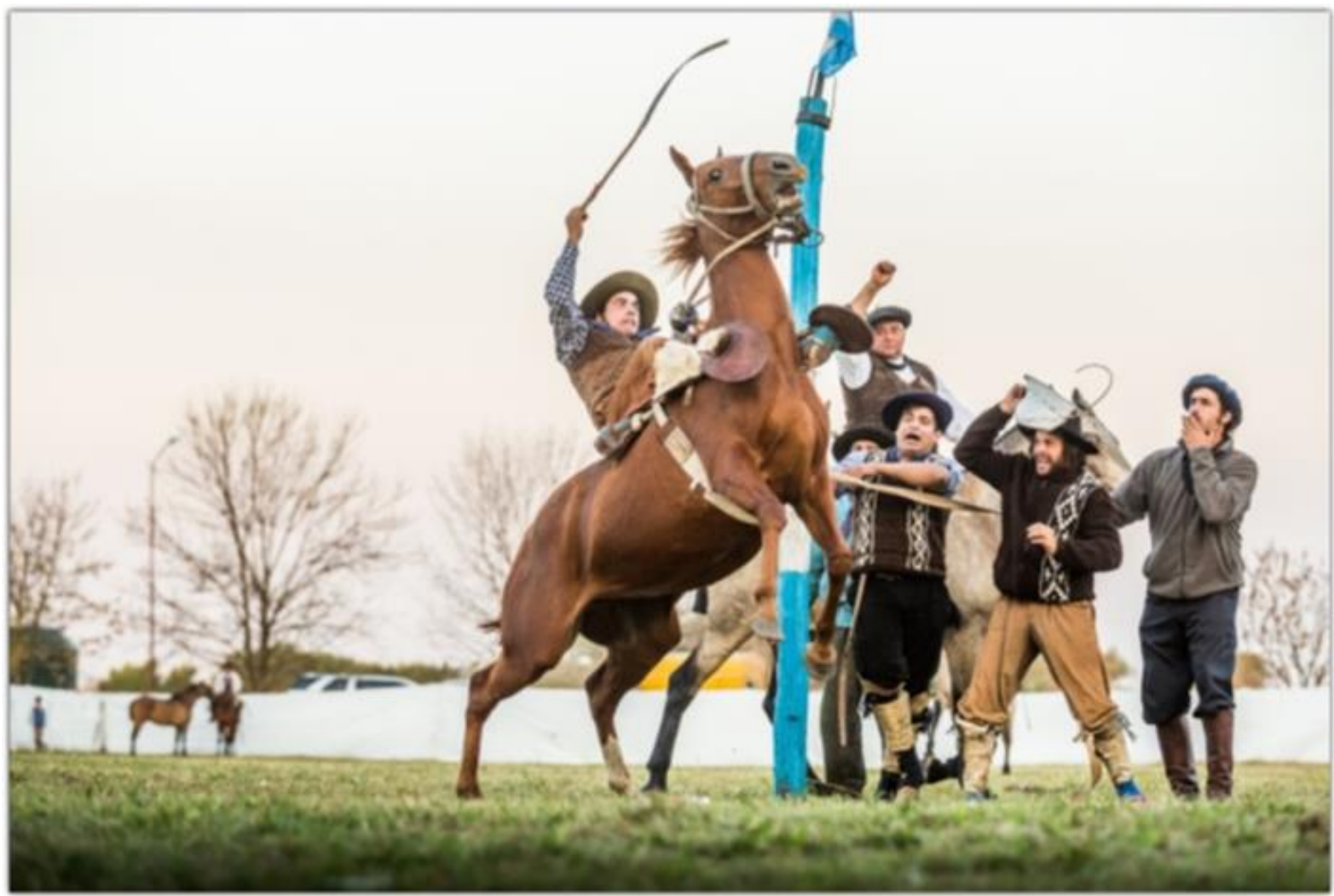

Figura 5 - Fotografia "El reservado" de Celine Frers (2015).

Fonte: FRERS, 2017.

A fotografia pode nos ensinar o que é natureza, o que é mulher, e onde está essa natureza que é destruída pelo humano. O humano aparece recorrentemente, como o devastador, e essa natureza dada como natural e virgem. Lembramos Ranciere (2012, p. 14), que diz: "A imagem nunca é uma realidade simples". Para o autor, as imagens são operações e, como tais, estão entre o dizível e o visível,

Formas visíveis propõem uma significação a ser compreendida ou a subtraem. Um movimento de câmara antecipa um espetáculo e descobre outro, um pianista inicia uma frase musical "atrás" de uma tela escura. Todas essas relações definem imagens. Isso quer dizer duas coisas. Em primeiro lugar, as imagens da arte, enquanto tais, são dessemelhanças. Em segundo lugar, a imagem não é uma exclusividade do visível. Há um visível que não produz imagem, há imagens que estão todas em palavras. Mas o regime mais comum da imagem é aquele que põe em cena uma relação do dizível com o visível, uma relação que joga ao mesmo tempo com sua analogia $e$ sua dessemelhança. Essa relação não exige de forma alguma que os dois termos estejam materialmente presentes. O visível se deixa dispor em tropos significativos, a palavra exibe uma visibilidade que pode cegar (RANCIERE, 2012, p. 15 e 16$)$ 
Assim que as fotografias trazem, provocam, operam relações e percepções. Tencionando esse modo de olhar para natureza como frágil e virgem, procuramos pensar nessas invenções em sua constituição, procurando problematizar como fomos nos tornando apartados e devastadores/colaborativos e protetores; assim como, reforçando marcas modernas do antropocentrismo e androcentrismo em que o homem aparece tanto como o destruidor e causador das mazelas ambientais como o ser que poderá dar conta dos tantos problemas ambientais.

\section{Considerações}

Entrelaçadas nessas teias discursivas, pinçamos mulheres, e colocamos algumas inquietações como potência para pensarmos as tramas discursivas que se articulam nesses jogos, nessas relações que se pautam na figura masculina e atribuem às mulheres, a tarefa do cuidado com a natureza.

Não se almeja uma resposta ou uma conclusão sobre o que articulamos na escrita, mas pensamos em consonância com Deleuze e Guattari (2007, p. 36)

Entre as coisas não designa uma correlação localizável que vai de uma para outra e reciprocamente, mas uma direção perpendicular, um movimento transversal que as carrega uma $e$ outra, riacho sem início nem fim, que rói suas duas margens e adquire velocidade no meio. (DELEUZE e GUATTARI, 2007 p. 36).

Nessa velocidade que escorre pelos meios, buscamos pensar sobre tantas verdades que nos constituem e muitas vezes a deixamos estáticas e intocáveis, enquanto a vida é movimento.

Assim pensamos no quanto esses discursos são fabricados em processos culturais, sustentados em relações de poder que fazem emergir verdades e saberes dados como naturais nos interstícios da educação ambiental.

\section{Referências}

ÁVILA, D. A. RIBEIRO, P.R.C. E HENNING, P.C. "O Gênero é fundamental para o desenvolvimento sustentável": reflexões sobre a operação de dispositivos em programas globais e seus efeitos para a Educação Ambiental. Rio Grande: REMEA, Ed. Especial, p.95119, julho/2016. Disponível em: https://www.seer.furg.br/remea/article/viewFile/5962/3685 Acesso em: 05 de setembro de 2016.

BRAIDOTTI, Rosi; CHARKIEWICZ, Ewa; HAUSLER, Sabine; WIERINGA, Saskia. Mulher, ambiente e desenvolvimento sustentável. Para uma síntese teórica. São Paulo: Instituto Piaget, 1994 
CARVALHO, I.C. de M. Educação ambiental: a formação do sujeito ecológico. São Paulo: Cortez, $6^{\mathrm{a} e d .,}$ 256p., 2012.

CASTRO, M.G.; ABRAMOPVAY, M. Gênero e Meio Ambiente. São Paulo: Cortez Editora, $2^{\circ}$ ed., 144p., 2005.

DELEUZE, G. Nietzsche e a Filosofia. Rio de Janeiro: Editora Rio - RJ. 1976.

DELEUZE, G., GUATTARI, F. Mil Platôs: capitalismo e esquizofrenia. vol. 1 São Paulo. Editora 34. 2007.

FRERS, C. Disponível em: http://www.celinefrers.com/fineart/gauchos Acesso em: 29 de junho de 2017.

GARCIA. S.M. Desfazendo os vínculos naturais entre gênero e meio ambiente. Revista de Estudos Feministas, Rio de Janeiro, v.0,n.0, p.163-68,1992. Disponível em: http://www.redalyc.org/pdf/381/38126508015.pdf Acesso em: 05 de setembro de 2016.

Google, 2018. Homem e Natureza. Disponível em: https://www.google.com.br/search?q=homem+e+natureza\&rlz=1C1EKKP_enBR797BR797 \&source=lnms\&tbm=isch\&sa=X\&ved=0ahUKEwi_nbrPkeDcAhWJhZAKHV1FAMUQ_AU ICigB\&biw=1242\&bih=557 Acesso em 09 de agosto de 2018.

Google, 2018. Mulher e Natureza. Disponível em: https://www.google.com.br/search?rlz=1C1EKKP_enBR797BR797\&biw=1242\&bih=557\&tb $\mathrm{m}=$ isch\&sa $=1 \& \mathrm{ei}=3$ UlsW6LhOIqnwATrji_gDg\&q=mulher+e+natureza\&oq=mulher+e+natu reza\&gs_l=img.3...60342.63487.0.65888.11.11.0.0.0.0.530.1624.0j1j2j1j0j1.5.0...0...1c.1.64. img..7.2.448...0i7i30k1j0i7i5i30k1j0i8i7i10i30k1j0i8i7i30k1.0.ysULdfMAGsk Acesso em 09 de agosto de 2018.

GRÜN, Mauro. Ética e Educação Ambiental: A conexão necessária. Campinas. Papirus. 1996.

GUATTARI, Félix. As Três Ecologias. São Paulo. Papirus. 1995.

FOUCAULT, Michel. A ordem do discurso. São Paulo. Editora Loyola. 2008.

, Michel. Estratégia, Poder - Saber / Ditos e Escritos IV. Rio de Janeiro. Forense Universitária. 2006.

RANCIÈRE, Jacques. O Destino das Imagens. Rio de Janeiro. Contraponto. 2012.

SCHLEE, R.L.; HENNING, P.C. Pensar uma história do presente: contribuições para olhar o Pampa Gaúcho. In: II Seminário Internacional Michel Foucault: Cinquentenário de As Palavras e as Coisas, Vol.I, 2016. Pelotas: Anais... Pelotas: UFPel, p. 514-532, 2016.

VEYNE, Paul M. Como se Escreve a História; Foucault revoluciona a História. Brasília. Universidade de Brasília. 2008. 
VIEIRA, V.T.; HENNING, P. C. A crise ambiental em evidência: análise do discurso foucaultiano - modos de fazer pesquisa em educação. Revista da Faeeba: Educação $e$ Contemporaneidade, Salvador, v.22,n.40, jul./dez. 2013. Disponível em: http://www.revistas.uneb.br/index.php/faeeba/article/view/764/537 Acesso em: 05 de setembro de 2016. 